\title{
Macrophage accumulation within coronary arterial wall in diabetic patients with acute coronary syndrome: a study with in-vivo intravascular imaging modalities
}

Takaaki Kogo, Takafumi Hiro * ${ }^{0}$, Daisuke Kitano, Tadateru Takayama, Daisuke Fukamachi, Tomoyuki Morikawa, Mitsumasa Sudo and Yasuo Okumura

This work was partly presented in the Annual Scientific Session of European Society of Cardiology, Barcelona, 2017.8

\begin{abstract}
Background and aims: Macrophage accumulation in arteriosclerotic plaque of coronary arteries is involved in plaque destabilization. Atherosclerosis has been known to be progressive in patients with type 2 diabetes mellitus (DM). This study compared the features of 3-dimensional (3D) spatial distribution of macrophage accumulation within coronary artery wall between acute coronary syndrome (ACS) patients with DM $(n=20)$ and those without (non-DM, $n=20$ ) by using intravascular ultrasound (IVUS) and optical coherence tomography (OCT).
\end{abstract}

Methods: The OCT-derived macrophage accumulation was measured within the proximal left anterior-descending artery. This measurement was performed for the whole vessel segment of interest, higher shear stress region (flow divider side) and lower shear stress region (the opposite side).

Results: Normalized macrophage accumulation per unit length of the whole segment of interest was significantly larger in ACS patients with DM than without. In non-DM patients, macrophage density per IVUS-derived plaque volume was significantly higher in high shear stress region compared to low shear stress region, however, there was no significant difference between the two regions in DM patients. The macrophage density in the low shear stress region was significantly higher in the DM group than in the non-DM group. A multivariate analysis showed that the presence of DM was a major determinant for macrophage distribution.

Conclusions: Macrophage accumulation was more abundant and homogeneous within coronary arterial wall in DM patients with ACS compared to non-DM patients, suggesting that plaque destabilization may occur more widely throughout coronary wall in DM patients.

Keywords: Acute coronary syndrome, Diabetes mellitus, Macrophage, Optical coherence tomography, Shear stress

${ }^{*}$ Correspondence: hiro.takafumi@nihon-u.ac.jp

Division of Cardiology, Department of Medicine, Nihon University School

of Medicine, 30-1 Oyaguchi-Kamicho Itabashi-ku, Tokyo 173-8610, Japan

\section{Background}

The main cause of acute coronary syndrome (ACS) is rupture of coronary plaque followed by thrombus formation [1]. Macrophage has been reported to play an important role during various steps of atherosclerosis up

(c) The Author(s) 2020. This article is licensed under a Creative Commons Attribution 4.0 International License, which permits use, sharing, adaptation, distribution and reproduction in any medium or format, as long as you give appropriate credit to the original author(s) and the source, provide a link to the Creative Commons licence, and indicate if changes were made. The images or other third party material in this article are included in the article's Creative Commons licence, unless indicated otherwise in a credit line to the material. If material is not included in the article's Creative Commons licence and your intended use is not permitted by statutory regulation or exceeds the permitted use, you will need to obtain permission directly from the copyright holder. To view a copy of this licence, visit http://creativeco mmons.org/licenses/by/4.0/. The Creative Commons Public Domain Dedication waiver (http://creativecommons.org/publicdomain/ zero/1.0/) applies to the data made available in this article, unless otherwise stated in a credit line to the data. 
to the plaque rupture [2-7]. Macrophages within plaque derived from migrated monocytes or smooth muscle cells phagocytose oxidized low-density lipoprotein (LDL) to become foamy cells and to form fatty streak and lipid core [8]. Macrophage secretes a wide variety of chemicals including IL-1 $\beta$ provoking local inflammation or matrix metalloproteinase which causes thinning of fibrous cap leading to higher vulnerability of plaque rupture [3-5]. Pathological examination of patients who died by ACS showed the involvement of inflammation accompanied by macrophages in both plaque rupture and erosion [6]. In addition, plaques of ACS patients have been shown to have a higher density of macrophages than plaques of stable angina pectoris [7]. In particular, those atherosclerotic processes have been more progressive in diabetes mellitus (DM) patients [9].

Macrophage infiltration into the vessel wall usually has localized heterogeneity throughout vessel wall partly due to heterogeneity of shear stress distribution. Several clinical and in vivo small animal studies of histological or multi-modality assessment of large and medium arteries have reported that macrophage infiltration can be observed more frequently in regions where shear stress is relatively higher, including an upstream side across stenotic plaque [10-14]. Nonetheless, whether or not underlying disease such as diabetes mellitus (DM) affects the distribution of macrophage infiltration within coronary arterial wall has not been clarified. Recently, intravascular optical coherence tomography (OCT) is considered to enable detect macrophage accumulation within coronary arterial wall [15-18]. Some previous studies have revealed with OCT that DM patients more likely have macrophage infiltration within coronary wall $[19,20]$, however, stereoscopic features of macrophage accumulation along the wall were not fully clarified. Therefore, the major purpose of the present study was to examine specific features of macrophage infiltration within coronary arterial wall in patients with ACS having type-2 diabetes mellitus (DM) using in vivo intravascular imaging modalities.

\section{Methods}

\section{Study patients}

This study was a single-center, retrospective, non-randomized study conducted from 2011 to 2017, which selected patients who met the following criteria: (1) Patients diagnosed as the first ACS to undergo coronary angiography (CAG) and percutaneous coronary intervention (PCI) at Nihon University Itabashi Hospital, (2) patients who underwent intravascular ultrasound (IVUS) and optical coherence tomography (OCT), and (3) patients who had a distinct OCT-derived coronary macrophage accumulation in the range of $20 \mathrm{~mm}$ from the entrance of the left anterior descending branch (LAD) (immediately after the left circumflex branch). ACS was defined as ST-elevation type acute myocardial infarction, non-ST elevation type myocardial infarction and unstable angina pectoris where there was no responsible lesion throughout the LAD. Patients with a history of coronary artery disease more than one month ago, those with a history of obvious stroke, chronic heart failure requiring treatment, aortic disease, or kidney disease, dialysis patients, those with liver disease, malignancy, thyroid diseases, familial hypercholesterolemia or poorly controlled hypertension, as well as those who had regularly use steroids or nonsteroidal antiinflammatory drugs during blood purification, immunization/chemotherapy including LDL apheresis were all excluded. Since the medical insurance system in Japan allowed us to use IVUS and OCT for the same patient only when IVUS imaging alone was so poor in image quality to perform percutaneous coronary interventions of the culprit lesion, the selection of patient examined was considerably limited. As a result, this study consisted of 40 patients, 20 patients with DM and 20 patients without it. The presence or absence of diabetes was judged from $\mathrm{HbA} 1 \mathrm{c}$ value at hospitalization of $6.5 \%$ or more, from the use of diabetes medication, and presence of the past history that diabetes was diagnosed by an attending physician. No patients with impaired glucose tolerance, which was a diabetes precursor condition, were included. All patients examined provided written informed consent for this study. This study was performed in accordance with the 1975 Declaration of Helsinki and approved by the Institutional Review Board of the Itabashi Hospital of Nihon University School of Medicine.

\section{IVUS and OCT procedure}

After performing regular CAG in the cardiac catheter examination, a guide wire was inserted to the periphery of the left anterior descending artery, and the following intravascular imaging was performed via the guide wire before PCI. Immediately before this test, $1.5 \mathrm{mg}$ of isosorbide dinitrate was injected into coronary artery. The observation range was from the periphery as far as possible through the entrance portion of LAD. Withdrawing of the imaging modalities was performed with an automatic constant speed. As for IVUS, OptiCross ${ }^{\mathrm{TM}}$ Imaging Catheter (iLab ${ }^{\mathrm{TM}}$ System, manufactured by Boston Scientific, Marlborough, MA) was used. The withdrawing speed was $0.5 \mathrm{~mm} / \mathrm{sec}$, and its frame-rate was 30 frames/sec. For OCT, Dragonfly ${ }^{\mathrm{TM}} \mathrm{JP}$ Imaging Catheter (ILUMIEN ${ }^{\mathrm{TM}}$, OPTIS ${ }^{\mathrm{TM}}$, St. Jude Medical, St. Paul, MN, USA) was used. The OCT imaging speed was $40 \mathrm{~mm} / \mathrm{sec}$ and the imaging frame-rate is 180 frames/ sec. Cases in which the quality of the image is bad, those 
with calcification at an elevation angle of 90 degrees or more within the measurement range are inappropriate for analysis were excluded. The vascular segment to be analyzed was selected as long as possible within $20 \mathrm{~mm}$ in length from the entrance of LAD. The following measurements of IVUS and OCT were performed blinded to clinical data.

\section{IVUS measurement}

In the Gray scale IVUS, the cross-sectional areas of vessel and lumen were first measured for every $0.5 \mathrm{~mm}$ interval within the segments of interest, and the plaque area was then calculated from the difference between the two areas [21]. The summation of the cross-section areas multiplied by $1 \mathrm{~mm}$ in length was calculated to obtain the total vessel volume, the total lumen volume, and the total plaque volume.

\section{OCT measurement and three-dimensional analysis of macrophage accumulation}

As measures on the tissue properties of the plaque segment examined by OCT, the minimum fibrous cap thickness as well as the maximum angular span of lipid core arc were determined [22]. In this study, the existence of macrophage accumulation was determined by OCT based on the presence of a line-like high luminance within the wall of the coronary artery having a striped shadow (Fig. 1a) [15]. In order to prevent contamination

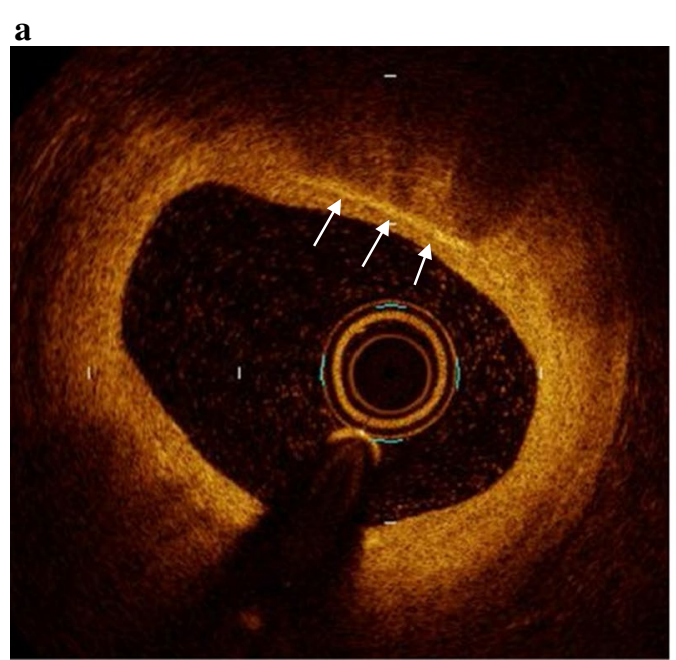

b

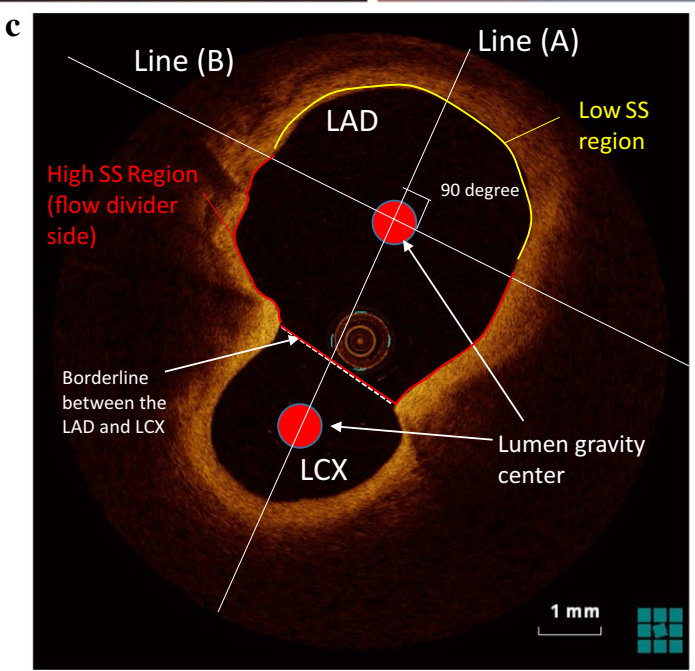

Fig. 1 OCT analysis of macrophage accumulation. a Representative two-dimensional image. A line-like high luminance within coronary having a striped shadow is considered as macrophage accumulation (arrows). The cross-sectional areas of the high luminance were measured to calculate macrophage accumulation volume using consecutive frame by frame OCT images within the proximal LAD segment of interest. $\mathbf{b}$ Representative three-dimensional image. Macrophage accumulation is indicated by pink color. c Definition of high and low shear stress regions. See main text for detail. LAD, the left anterior descending artery; LCX, left circumflex artery; SS, shear stress 
of artifacts, the findings were assumed to be recognized over three consecutive frames on the OCT. The identification of macrophage accumulation was automatically performed by extracting a region equal to or higher than a certain luminance with use of three-dimensional image analysis software AVIZO ${ }^{\mathrm{TM}}$ (ver 6.2.1, MAXNET Corporation, Tokyo). In this analysis, erroneously extracted portions was excluded with visual inspection by an experienced observer. The area of macrophage accumulation was then displayed in 3D reconstructed image (Fig. 1b). Finally, the volume of the macrophage accumulation within the vascular segment of interest was automatically calculated from the summation of the area of each frame by the AVIZO software. The feasibility of the AVIZO in measuring 3D volume microstructure has been warranted in previous studies [23].

The coronary artery in the range of $20 \mathrm{~mm}$ from the LAD entrance part was next divided into two parts, the branch side half and the opposite side half, looking at the branching of the left circumflex (LCX) (Fig. 1c). At the LAD/LCX bifurcation cross-section, the centers of gravity of both blood vessel branches were first connected by a straight line (A). The straight line (B) orthogonal to the straight line (A) passing through the lumen gravity center of the LAD was then drawn. This line (B) divided the LAD wall into two regions on the LCX branch side and on the opposite side. The LCX side half, in other words, flow divider side, can be considered as a high shear-stress region, and the opposite side half as a low shear-stress region [24]. Considering the difference in observation range between the groups, normalized volume of the macrophage accumulation (per 1-mm-length) was also measured. Furthermore, macrophage accumulation density of total plaque and high- or low-shear stress region was also calculated by dividing the accumulated volume of the macrophage by each plaque volume of total and high- or low-shear stress region, respectively. The corresponded plaque volume was obtained from IVUS imaging, because visualization of the whole plaque is frequently difficult due to the limited penetration depth of the infra-red ray in OCT imaging.

\section{Statistical analysis}

Values are shown as mean \pm standard deviation, median [confidence interval (CI)], or number (percentages). For the comparison between the two groups, the $\chi^{2}$ test for the category variable and the $t$ test for the continuous variable were performed. In the case where the continuous variable does not give a normal distribution, a Mann-Whitney test was used. In multivariate analysis, binary logistic regression analysis was performed where the explanatory variable which had a $\mathrm{p}<0.2$ in univariate analysis could be included. In this analysis, the presence of diabetes mellitus, hyper-uric-acidemia, value of HDL cholesterol, the minimum fibrous cap thickness, normalized total vessel volume and normalized plaque volume in the assumed low shear stress region and plaque volume were included. Statistical analysis was performed using IBM SPSS Statistics 24.0 (IBM, New York City, USA), and the p value less than 0.05 was determined to be statistically significant.

\section{Results}

Patients characteristics (Table 1)

Baseline characteristics per study group were summarized in Table 1. Average age and gender did not differ between the 2 groups. The frequency of ST elevation myocardial infarction was significantly higher in the non-DM group $(\mathrm{p}=0.01)$, but those of non-ST elevation myocardial infarction and unstable angina were not significantly different between the two groups. The prevalence of coronary risk factors also did not differ between the two groups except for diabetes medicines. As for laboratory data, the value of $\mathrm{HbA1c}$ was significantly higher in the DM group than the non-DM group $(8.0 \pm 2.4 \%$ vs. $5.7 \pm 0.2 \%, p=0.001)$. However, no other laboratory items differed significantly between the two groups.

\section{IVUS findings (Table 2)}

The observation length was statistically comparable between the two groups (median value: $13.1 \mathrm{~mm}, \mathrm{CI} 9.0$ $19.3 \mathrm{~mm}$ in the DM group and $16.5 \mathrm{~mm}$, CI $14-20 \mathrm{~mm}$ in the non-DM group). The analysis by Gray scale IVUS showed that there was no significant difference in terms of IVUS measurement except for lumen volume, although normalized lumen volume (per 1-mm-length) was not significantly different between the groups. When comparing plaque volume in the high shear stress region and that low shear region between the groups, no significant difference was found regarding the absolute value as well as normalized value (per 1-mm-length).

\section{OCT findings (Table 3 )}

The minimum fibrous cap thickness was significantly thinner in the DM group than the non-DM group $(81.5 \pm 17.3 \mu \mathrm{m}$ vs. $99.5 \pm 29.8 \mu \mathrm{m}, \mathrm{p}=0.025)$. In the high shear stress region, the minimum fibrous cap thickness was not significantly different between the two groups. However, in the low shear stress region, this thickness was significantly thinner in the DM group than the nonDM group $(92 \pm 20.9 \mu \mathrm{m}$ vs. $125 \pm 29.8 \mu \mathrm{m}, \mathrm{p}<0.0001)$. The maximum lipid core angle was not different between the two groups as for the entire vascular region of interest as well as the high or low shear stress regions. 
Table 1 Patients characteristics

\begin{tabular}{|c|c|c|c|}
\hline & $D M(n=20)$ & non-DM $(n=20)$ & $p$ value \\
\hline Age (years) & $64.2 \pm 12.1$ & $66.6 \pm 15.9$ & 0.593 \\
\hline Gender, male (\%) & $15(75)$ & $12(60)$ & 0.311 \\
\hline STEMI, n (\%) & $8(40)$ & $16(80)$ & 0.010 \\
\hline NSTEMI, n (\%) & $5(25)$ & $1(5)$ & 0.091 \\
\hline UAP, n (\%) & $7(35)$ & $3(15)$ & 0.137 \\
\hline \multicolumn{4}{|l|}{ Risk factor } \\
\hline Hypertension, n (\%) & $13(65)$ & $10(50)$ & 0.337 \\
\hline Dyslipidemia, n (\%) & $10(50)$ & $12(60)$ & 0.525 \\
\hline Hyperuremia, n (\%) & $4(20)$ & $1(5)$ & 0.342 \\
\hline Obesity, n (\%) & $8(40)$ & $4(20)$ & 0.168 \\
\hline Smoker, n (\%) & $11(55)$ & $8(40)$ & 0.342 \\
\hline Family history, n (\%) & $4(20)$ & $2(10)$ & 0.661 \\
\hline \multicolumn{4}{|l|}{ Medication } \\
\hline Aspirin, n (\%) & $4(20)$ & $1(5)$ & 0.342 \\
\hline $\begin{array}{l}\text { Calcium channel blocker, } \\
\text { n (\%) }\end{array}$ & $6(30)$ & $7(35)$ & 0.736 \\
\hline ACEI/ARB, n (\%) & $9(45)$ & $4(20)$ & 0.091 \\
\hline Beta blocker, n (\%) & $4(20)$ & $0(0)$ & 0.106 \\
\hline Diuretics, n (\%) & $1(5)$ & $1(5)$ & 1.000 \\
\hline Statin, n (\%) & $5(25)$ & $3(15)$ & 0.695 \\
\hline Antidiabetic drug, n (\%) & $11(55)$ & $0(0)$ & $<0.0001$ \\
\hline Sulfonylurea, n (\%) & $4(20)$ & $0(0)$ & 0.106 \\
\hline DPP-4 inhibitor, n (\%) & $8(40)$ & $0(0)$ & 0.003 \\
\hline Insulin, n (\%) & $1(5)$ & $0(0)$ & $<0.0001$ \\
\hline \multicolumn{4}{|l|}{ Laboratory findings } \\
\hline Hemoglobin (g/dl) & $13.3 \pm 2.2$ & $13.0 \pm 2.4$ & 0.751 \\
\hline Creatinine (mg/dl) & $0.93 \pm 0.45$ & $0.75 \pm 0.16$ & 0.116 \\
\hline BUN (mg/dl) & $19.0 \pm 11.7$ & $14.1 \pm 4.4$ & 0.091 \\
\hline $\operatorname{eGFR}\left(\mathrm{ml} / \mathrm{min} / 1.73 \mathrm{~m}^{2}\right)$ & $68.7 \pm 23.6$ & $76.6 \pm 23.2$ & 0.296 \\
\hline Total-C (mg/dl) & $206.0 \pm 50.7$ & $206.8 \pm 42.0$ & 0.957 \\
\hline $\mathrm{HDL}-\mathrm{C}(\mathrm{mg} / \mathrm{dl})$ & $39.8 \pm 8.1$ & $45.1 \pm 13.7$ & 0.157 \\
\hline $\mathrm{LDL}-\mathrm{C}(\mathrm{mg} / \mathrm{dl})$ & $131.1 \pm 44.8$ & $132.5 \pm 33.3$ & 0.916 \\
\hline $\mathrm{TG}(\mathrm{mg} / \mathrm{dl})$ & $173.6 \pm 119.9$ & $111.1 \pm 70.7$ & 0.058 \\
\hline HbA1c(NGSP) (\%) & $8.0 \pm 2.4$ & $5.7 \pm 0.2$ & 0.001 \\
\hline $\mathrm{UA}(\mathrm{mg} / \mathrm{dl})$ & $5.8 \pm 1.8$ & $5.5 \pm 1.5$ & 0.550 \\
\hline $\mathrm{hsCRP}(\mathrm{mg} / \mathrm{dl})$ & $0.21 \pm 0.15$ & $0.21 \pm 0.37$ & 1.000 \\
\hline
\end{tabular}

Data were expressed as number (percentage) or mean value \pm standard deviation

\section{Characteristics of macrophage accumulation (Table 4)}

When comparing indices between the DM and the non-DM groups, normalized volume of macrophage accumulation (per 1-mm-length) in the total vessel segment of interest as well as in the low-shear stress region was significantly larger in the DM group $(p=0.015$ and $\mathrm{p}=0.002$, respectively) compared to the non-DM group. However, this value was not significantly different between the two groups in the high shear stress region $(\mathrm{p}=0.999)$. Regarding macrophage density (per plaque volume), this value of the DM group had a higher tendency in the total vessel segment of interest $(p=0.060)$, and was significantly higher in the low-shear stress region $(\mathrm{p}=0.003)$ compared to the non-DM group.

On the other hand, when comparing each index between the high and the low shear stress regions (Fig. 2), normalized volume of macrophage accumulation of the non-DM group had a larger tendency $(\mathrm{p}=0.096)$, and its macrophage density was significantly higher $(p=0.030)$ in the high shear stress region. However, both indices of the DM group were comparable between the regions ( $\mathrm{p}=0.314$ and $\mathrm{p}=0.565$. respectively).

On the basis of the data above, a multivariate analysis in order to reveal significant determinants for the distribution pattern of macrophage accumulation was performed. The objective value used [(macrophage accumulation density in high shear stress region) minus (macrophage accumulation density in low shear stress region)]/(accumulation density of macrophage in the whole region). This index was formed, because some plaque had no macrophage infiltration at all and simple calculation of the ratio of macrophage accumulation volume between the two sides was difficult in such cases. As a result, only the presence of diabetes mellitus was a significant regulatory factor $(\mathrm{p}=0.033)$ (Table 5$)$.

\section{Discussion}

The major finding of the present study with using threedimensional OCT and IVUS was that macrophage accumulation was more frequent in DM patients with ACS compared to non-DM patients, even indicating that its distribution pattern was significantly different in such patients. Macrophage was more accumulated in the flowdivider (higher shear stress) region in non-DM patients with ACS than the opposite (lower shear stress) region. However, the difference was significantly attenuated in DM patients with ACS, while macrophage infiltration was more frequent within the opposite (lower shear stress) region, suggesting homogeneous distribution of macrophage accumulation along the coronary wall. Furthermore, among various risk factors the presence of DM might play a pivotal role in the distribution pattern of macrophage accumulation, according to a multivariate analysis.

\section{Diabetes and macrophage accumulation}

Difference in tissue characteristics of coronary plaque between DM and non-DM patients have been reported in many previous necropsy or in vivo angiography, IVUS and OCT studies [25-32]. Necropsy examinations have shown that DM patients had a greater necrotic core, a thinner fibrous cap, increased macrophage infiltration and healed ruptured plaque within coronary arterial 
Table 2 IVUS findings

\begin{tabular}{lccc}
\hline & DM $(\mathbf{n}=\mathbf{2 0})$ & non DM $(\mathbf{n}=\mathbf{2 0})$ & $\mathbf{p}$ value \\
\hline Segment length & $13.1(9.0-19.3)$ & $16.5(14.0-20.0)$ & 0.063 \\
Lumen volume $\left(\mathrm{mm}^{3}\right)$ & $81.5(55.5-121.5)$ & $138.1(123.8-195.8)$ & 0.004 \\
Vessel volume $\left(\mathrm{mm}^{3}\right)$ & $225.7(137.4-285.5)$ & $269.0(216.8-388.4)$ & 0.096 \\
Plaque volume $\left(\mathrm{mm}^{3}\right)$ & $131.3(80.4-160.4)$ & $129.1(95.9-164.7)$ & 0.925 \\
Plaque volume of high SS region $\left(\mathrm{mm}^{3}\right)$ & $58.7(35.6-73.7)$ & $58.8(35.9-68.9)$ & 1.000 \\
Plaque volume of low SS region $\left(\mathrm{mm}^{3}\right)$ & $63.5(51.9-89.9)$ & $67.1(51.1-92.2)$ & 0.620 \\
Normalized lumen volume/1 $\mathrm{mm}\left(\mathrm{mm}^{3} / \mathrm{mm}\right)$ & $7.3(5.8-9.2)$ & $15.4(6.8-11.2)$ & 0.174 \\
Normalized vessel volume $/ 1 \mathrm{~mm}\left(\mathrm{~mm}^{3} / \mathrm{mm}\right)$ & $16.5(14.3-22.2)$ & $7.8(6.1-9.7)$ & 0.758 \\
Total normalized plaque volume $\left(\mathrm{mm}^{3} / \mathrm{mm}\right)$ & $9.5(7.4-12.0)$ & $3.2(2.7-4.8)$ & 0.068 \\
Normalized plaque volume in high SS region $\left(\mathrm{mm}^{3} / \mathrm{mm}\right)$ & $4.3(3.4-5.6)$ & $4.5(3.4-5.5)$ & 0.072 \\
Normalized plaque volume in low SS region $\left(\mathrm{mm}^{3} / \mathrm{mm}\right)$ & $5.8(3.5-6.9)$ & & 0.081 \\
\hline
\end{tabular}

Values are expressed as median value (confidence interval). SS, shear stress

Table 3 OCT findings

\begin{tabular}{|c|c|c|c|}
\hline & $\mathrm{DM}(\mathrm{n}=20)$ & Non DM $(n=20)$ & $p$ value \\
\hline Fibrous cap thickness ( $\mu m)$ & $81.5 \pm 17.3$ & $99.5 \pm 29.8$ & 0.025 \\
\hline Minimum fibrous cap thickness in high SS Region $(\mu \mathrm{m})$ & $94 \pm 23.5$ & $104 \pm 39.8$ & 0.339 \\
\hline Minimum fibrous cap thickness in low SS region $(\mu \mathrm{m})$ & $92 \pm 20.9$ & $125 \pm 29.8$ & $<0.0001$ \\
\hline Maximum lipid arc (degree) & $146.6 \pm 35.2$ & $127.4 \pm 27.8$ & 0.063 \\
\hline Maximum lipid arc in high SS region (degree) & $105.8 \pm 32.6$ & $85.5 \pm 36.2$ & 0.070 \\
\hline Maximum lipid arc in low SS region (degree) & $119.8 \pm 39.0$ & $110.5 \pm 37.1$ & 0.446 \\
\hline
\end{tabular}

Values are expressed as median value (confidence interval). SS, shear stress

Table 4 Characteristics of OCT-derived macrophage accumulation in DM and non-DM patients with ACS

\begin{tabular}{|c|c|c|c|}
\hline & $\mathrm{DM}(\mathrm{n}=20)$ & non DM $(n=20)$ & p value \\
\hline Total normalized M-Vol (mm³/mm) & $9.5 \times 10^{-3}\left(4.2 \times 10^{-3}-12.5 \times 10^{-3}\right)$ & $2.9 \times 10^{-3}\left(1.4 \times 10^{-3}-11.3 \times 10^{-3}\right)$ & 0.015 \\
\hline Normalized M-Vol in high SS region $\left(\mathrm{mm}^{3} / \mathrm{mm}\right)$ & $1.9 \times 10^{-3}\left(0.4 \times 10^{-3}-7.8 \times 10^{-3}\right)$ & $2.1 \times 10^{-3}\left(0.5 \times 10^{-3}-8.0 \times 10^{-3}\right)$ & 0.999 \\
\hline normalized M-Vol in low SS region ( $\left.\mathrm{mm}^{3} / \mathrm{mm}\right)$ & $4.0 \times 10^{-3}\left(2.2 \times 10^{-3}-9.7 \times 10^{-3}\right)$ & $0.8 \times 10^{-3}\left(0.2 \times 10^{-3}-2.1 \times 10^{-3}\right)$ & 0.002 \\
\hline p value between high SS and low SS regions & 0.314 & 0.096 & \\
\hline Total M-density & $9.9 \times 10^{-4}\left(4.1 \times 10^{-4}-12.9 \times 10^{-4}\right)$ & $4.5 \times 10^{-4}\left(2.1 \times 10^{-4}-11.9 \times 10^{-4}\right)$ & 0.060 \\
\hline M-density in high SS region & $5.6 \times 10^{-4}\left(1.1 \times 10^{-4}-18.8 \times 10^{-4}\right)$ & $7.1 \times 10^{-4}\left(1.4 \times 10^{-4}-16.5 \times 10^{-4}\right)$ & 0.779 \\
\hline M-density in low SS region & $6.5 \times 10^{-4}\left(4.5 \times 10^{-4}-15.1 \times 10^{-4}\right)$ & $1.5 \times 10^{-4}\left(0.5 \times 10^{-4}-4.5 \times 10^{-4}\right)$ & 0.003 \\
\hline p value between high SS and low SS regions & 0.565 & 0.030 & \\
\hline
\end{tabular}

Values are expressed as median value (confidence interval). M-vol, macrophage accumulation volume; SS, shear stress; M-density, macrophage accumulation density per IVUS-derived plaque volume

wall compared to non-DM patients [25, 26, 33]. Among in vivo studies, coronary angiographic studies have shown that coronary artery lesion is more severe, extended, diffuse and multivessel in DM patients [27]. IVUS examinations have revealed that coronary plaque of DM patients is more abundant with a larger necrotic core and limited vascular remodeling [28-30, 34, 35]. More recently, studies with use of OCT have shown that DM patients had a larger lipid arc, a thinner fibrous cap, and a higher prevalence of calcification and mural thrombus [31, 32,
36, 37]. The results of our own support these data; the normalized plaque volume tended to be greater, and the maximum lipid arc tended to be greater in patients with DM compared with those without in our study. Furthermore, our data uniquely showed characteristics of macrophage accumulation pattern in DM patients with ACS, suggesting more abundant as well as more homogeneous macrophage infiltration within coronary wall, compared to non-DM patients. Previous studies have shown that DM patients have likely more abundant macrophage 


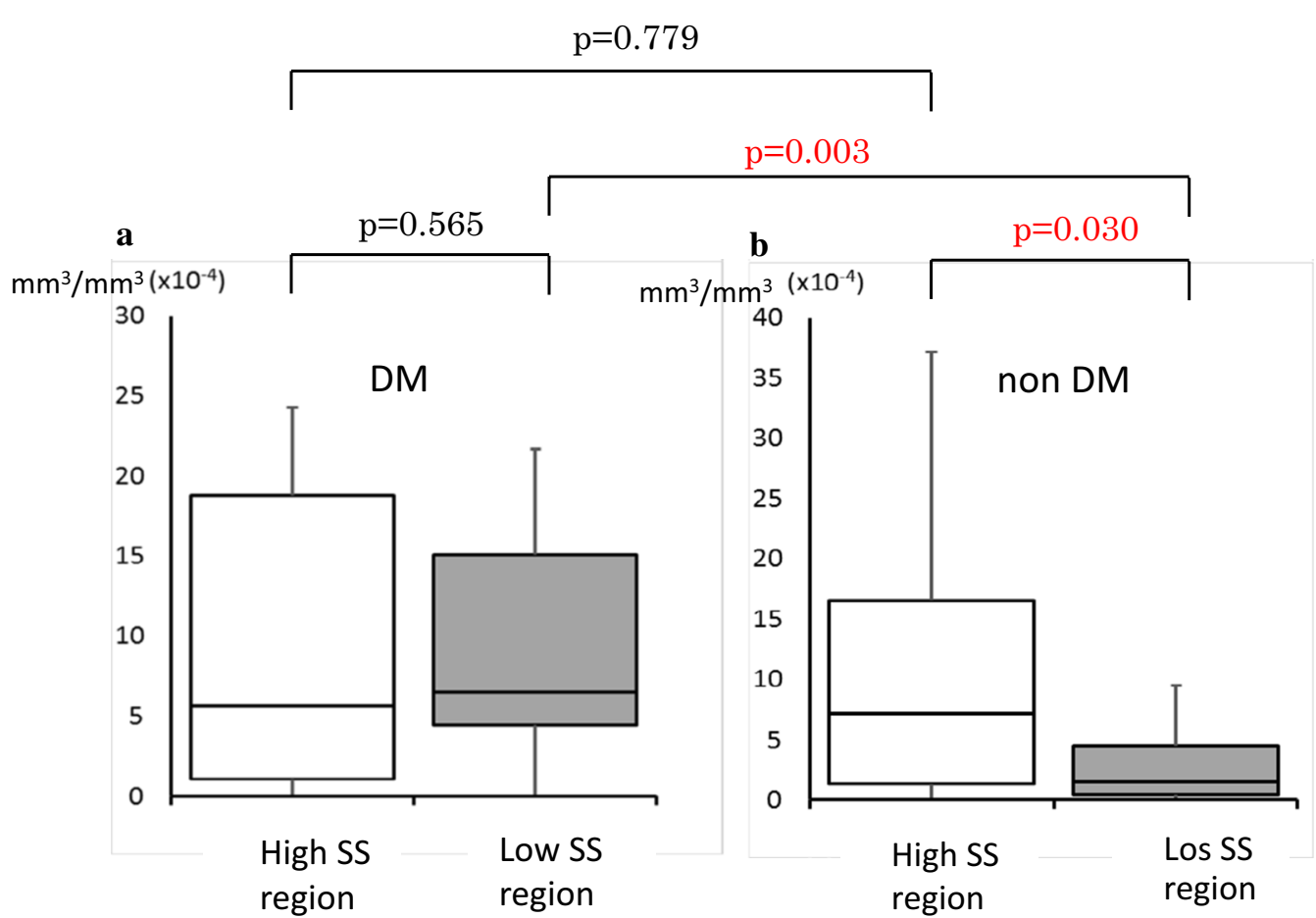

Fig. 2 Comparisons of macrophage density per plaque volume between high and low shear stress regions, and between diabetic and non-diabetic patients. DM, type 2 diabetes mellitus; SS, shear stress

Table 5 Multivariate analysis for determinant of macrophage accumulation distribution pattern

\begin{tabular}{lll}
\hline Variables & Odds ratio & p value \\
\hline Diabetes mellitus & 0.086 & 0.033 \\
Hyperuremia & 0.278 & 0.338 \\
HDL-C & 0.993 & 0.853 \\
Minimum fibrous cap thickness in low SS region & 0.97 & 0.069 \\
Normalized plaque volume in low SS region & 0.086 & 0.777 \\
Total normalized vessel volume & 0.777 & 0.060 \\
\hline
\end{tabular}

The objective value of macrophage accumulation distribution pattern is calculated from [(macrophage accumulation density in high shear stress region) minus (macrophage accumulation density in low shear stress region)]/ (accumulation density of macrophage in the whole region). SS, shear stress

accumulation within coronary arterial wall [16-18], however, these studies did not examine difference in the distribution pattern of macrophage infiltration.

Increased inflammatory markers and mediators have been observed in patients with type 2 DM [38-40]. Increased and activated macrophages in DM patients express scavenger receptors to more aggressively engulf oxidized low-density lipoprotein followed by forming foam cells and leading to production of chemokine to promote atherosclerosis. Furthermore, cholesterol crystals captured by macrophage yields inflammasome complex activation [41] producing interleukin-1 beta to provide a feed forward mechanism to amplify atherosclerosis. In DM patients, all of these may be accelerated $[25,42,43]$, which may support our data in which macrophage accumulation was more increased in DM patients.

\section{Shear stress and macrophage accumulation}

The distribution of macrophage accumulation may be mainly determined by heterogeneity of shear stress on the coronary intimal surface. It has been well known that atherosclerotic plaque volume progression can be observed more frequently in a lower shear stress region $[44,45]$. However, the role of shear stress in plaque destabilization is under controversy, but considerable number of reports have documented that high shear stress plays an important role in plaque destabilization [46-50], including enhanced extracellular matrix degradation [51, 52], thinning of fibrous cap [51-53] and increasing of necrotic core [53]. The present study also provided the similar observations, for example, plaque volume appeared to be greater in low-shear stress regions compared with high-shear stress regions, while lipid arc appeared to be greater in high-shear stress regions compared with low-shear stress regions, although it did not reach statistical significance. Moreover, macrophage 
has been found to be more frequently accumulated in a higher shear stress region in vascular wall [10-14], which is comparable to the data of our own in non-DM patients.

Some discrepancies between low shear stress theory that enhances plaque progression and high shear stress that enhances macrophage accumulation and plaque destabilization may be explained as follows: High shear stress actually enhances endothelial NO secretion which has been shown to have anti-inflammatory effects [54], however, it has been shown that high shear stress induces increased expression of endothelial adhesion molecules, such as ICAM and VCAM, resulting in enhanced monocyte adherence followed by increasing macrophage formation within atherosclerotic plaque $[10,53]$. Therefore, plaque tissue modification may be determined by the balance among these contradictory factors.

In the present study, macrophage was accumulated within coronary wall more homogeneously regardless of shear stress degree in DM patients with ACS. It was especially interesting that macrophage accumulation was more enhanced in the lower shear stress region in DM patients with ACS. This may be not only due to a change of the balance described above, but also due to substantial endothelial dysfunction, which has been commonly observed in DM patients [42, 43, 55]. Significant endothelia dysfunction in DM may deteriorate shearstress-dependent mechanism of determining coronary tissue characteristics followed by homogeneous macrophage accumulation.

\section{Study limitations}

There are limitations in the present study. This study was a single-center, retrospective study. The number of patients examined was relatively small, and assessment of macrophage accumulation was limited to LAD segment where the influence of curvature was considered to be relatively small. Clinical profiles except diabetic parameters between DM and non-DM group could not be completely matched, for example, STEMI was more frequent in non-DM patients than in DM ones, and this limitation should be considered in interpreting our data. In addition, the target vessel segment was divided into two parts, flow divider side and the opposite side, which were assumed to be a higher and a lower shear stress regions, respectively [24]. However, the absolute value of shear stress was not measured, the measurement of which was actually hardly possible in clinical settings.

In this study we detected macrophage accumulation within coronary arterial wall not by direct histopathological way but by in vivo OCT which had some inherent limitations [22], which should be considered in interpreting out results.

\section{Conclusions}

Macrophage accumulation was more abundant and homogeneous within coronary arterial wall in DM patients with ACS compared to non-DM patients, suggesting that plaque destabilization may occur more widely throughout coronary wall in DM patients.

\section{Abbreviations}

ACS: Acute coronary syndrome; CAG: Coronary angiography; DM: Diabetes mellitus; IVUS: Intravascular ultrasound; LAD: Left anterior descending branch; LCX: Left circumflex branch; LDL: Low-density lipoprotein; OCT: Optical coherence tomography; PCl: Percutaneous coronary intervention; 3D: 3-dimensional.

\section{Acknowledgements}

Not applicable.

\section{Authors' contributions}

All authors provide (1) substantial contributions to the conception or design of the work; or the acquisition, analysis, or interpretation of data for the work, (2) drafting the work or revising it critically for important intellectual content, (3) final approval of the version to be published and (4) agreement to be accountable for all aspects of the work in ensuring that questions related to the accuracy or integrity of any part of the work are appropriately investigated and resolved. All authors read and approved the final manuscript.

\section{Funding}

This work was partly supported by a Grant-in-Aid for Scientific Research (JSPS KAKENHI Grant Number 16K09481) of the Ministry of Education, Japan.

\section{Availability of data and materials}

The datasets used and/or analysed during the current study are available from the corresponding author on reasonable request.

\section{Ethics approval and consent to participate}

All patients examined provided written informed consent for this study. This study was performed in accordance with the 1975 Declaration of Helsinki and approved by the Institutional Review Board of the Itabashi Hospital of Nihon University School of Medicine.

\section{Consent for publication}

Not applicable.

\section{Competing interests}

Dr. Hiro worked at the endowed department at Nihon University School of Medicine donated by Boston-Scientific Japan Co. Ltd, a manufacturer of IVUS machine used in the present study. Dr, Kitano worked at the endowed department at Nihon University School of Medicine donated by Boston-Scientific Japan Co. Ltd, a manufacturer of IVUS machine used in the present study. Dr. Okumura worked at the endowed department at Nihon University School of Medicine donated by Boston-Scientific Japan Co. Ltd, a manufacturer of IVUS machine used in the present study.

Received: 9 May 2020 Accepted: 29 August 2020

Published online: 05 September 2020

\section{References}

1. Davies MJ, Thomas AC. Plaque fissuring: the cause of acute myocardial infarction, sudden ischaemic death, and crescendo angina. Br Heart J. 1985:53:363-73.

2. Falk E, Nakano M, Bentzon JF, Finn AV, Virmani R. Update on acute coronary syndromes: the pathologists' view. Eur Heart J. 2013;34(10):719-28.

3. Galis ZS, Sukhova GK, Kranzhöfer R, Clark S, Libby P. Macrophage foam cells from experimental atheroma constitutively produce matrix-degrading proteinases. Proc Natl Acad Sci USA. 1995;92(2):402-6. 
4. Shah PK, Falk E, Badimon JJ, Fernandez-Ortiz A, Mailhac A, Villareal-Levy G, Fallon JT, Regnstrom J, Fuster V. Human monocyte-derived macrophages induce collagen breakdown in fibrous caps of atherosclerotic plaques. Potential role of matrix-degrading metalloproteinases and implications for plaque rupture. Circulation. 1995;92(6):1565-9.

5. Libby P, Geng YJ, Aikawa M, Schoenbeck U, Mach F, Clinton SK, Sukhova GK, Lee RT. Macrophages and atherosclerotic plaque stability. Curr Opin Lipidol. 1996;7(5):330-5.

6. van der Wal $A C$, Becker AE, van der Loos CM, Das PK. Site of intimal rupture or erosion of thrombosed coronary atherosclerotic plaques is characterized by an inflammatory process irrespective of the dominant plaque morphology. Circulation. 1994;89(1):36-44.

7. Moreno PR, Falk E, Palacios IF, Newell JB, Fuster V, Fallon JT. Macrophage infiltration in acute coronary syndromes, Implications Plaque Rupture. Circulation. 1994;90(2):775-8.

8. Ross R. Cell biology of atherosclerosis. Annu Rev Physiol. 1995;57:791-804.

9. Kannel WB, MCGee DL. Diabetes and cardiovascular risk factors: the Framingham study. Circulation. 1979;59(1):8-13.

10. Dirksen MT, van der Wal AC, van den Berg FM, van der Loos CM, Becker AE. Distribution of inflammatory cells in atherosclerotic plaques relates to the direction of flow. Circulation. 1998;98(19):2000-3.

11. Fagerberg B, Ryndel M, Kjelldahl J, Akyürek LM, Rosengren L, Karlström L, Bergström G, Olson FJ. Differences in lesion severity and cellular composition between in vivo assessed upstream and downstream sides of human symptomatic carotid atherosclerotic plaques. J Vasc Res. 2010;47(3):221-30.

12. Yilmaz A, Lipfert B, Cicha I, Schubert K, Klein M, Raithel D, Daniel WG, Garlichs CD. Accumulation of immune cells and high expression of chemokines/chemokine receptors in the upstream shoulder of atherosclerotic carotid plaques. Exp Mol Pathol. 2007;82(3):245-55.

13. Segers $D$, Helderman $F$, Cheng $C$, van Damme LC, Tempel D, Boersma E, Serruys PW, de Crom R, van der Steen AF, Holvoet P, Krams R. Gelatinolytic activity in atherosclerotic plaques is highly localized and is associated with both macrophages and smooth muscle cells in vivo. Circulation. 2007;115(5):609-16.

14. Tropea BI, Huie P, Cooke JP, Tsao PS, Sibley RK, Zarins CK. Hypertensionenhanced monocyte adhesion in experimental atherosclerosis. J Vasc Surg. 1996;23(4):596-605.

15. Tearney GJ, Yabushita H, Houser SL, Aretz HT, Jang IK, Schlendorf KH, Kauffman CR, Shishkov M, Halpern EF, Bouma BE. Quantification of macrophage content in atherosclerotic plaques by optical coherence tomography. Circulation. 2003;107(1):113-9.

16. Taguchi Yuya, Itoh Tomonori, Oda Hideto, Uchimura Yohei, Kaneko Kyosuke, Sakamoto Tsubasa, Goto Iwao, Sakuma Masafumi, Ishida Masaru, Terashita Daisuke, Otake Hiromasa, Morino Yoshihiro, Shinke Toshiro. Coronary risk factors associated with OCT macrophage images and their response after CoCr everolimus-eluting stent implantation in patients with stable coronary artery disease. Atherosclerosis. 2017;265:117-23.

17. Reith Sebastian, Battermann Simone, Hoffmann Rainer, Marx Nikolaus, Burgmaier Mathias. Optical coherence tomography derived differences of plaque characteristics in coronary culprit lesions between type 2 diabetic patients with and without acute coronary syndrome. Catheter Cardiovasc Interv. 2014;84(5):700-7

18. Burgmaier Mathias, Hellmich Martin, Marx Nikolaus, Reith Sebastian. A score to quantify coronary plaque vulnerability in high-risk patients with type 2 diabetes: an optical coherence tomography study. Cardiovasc Diabetol. 2014;21(13):117

19. Zhang S, Dai J, Jia H, Hu S, Du H, Li N, Zou Y, Zou Y, Jing S, Wang Y, Sun $R$, Yu B. Non-culprit plaque characteristics in acute coronary syndrome patients with raised hemoglobinA1c: an intravascular optical coherence tomography study. Cardiovasc Diabetol. 2018;17(1):90.

20. Sugiyama T, Yamamoto E, Bryniarski K, Xing L, Fracassi F, Lee H, Jang IK. Coronary Plaque characteristics in patients with diabetes mellitus who presented with acute coronary syndromes. J Am Heart Assoc. 2018;7(14):e009245.

21. Mintz GS, Nissen SE, Anderson WD, Bailey SR, Erbel R, Fitzgerald PJ, Pinto FJ, Rosenfield K, Siegel RJ, Tuzcu EM, Yock PG. American College of Cardiology Clinical Expert Consensus Document on Standards for Acquisition, Measurement and Reporting of Intravascular Ultrasound Studies (IVUS) A Report of the American College of Cardiology Task Force on Clinical Expert Consensus Documents. J Am Coll Cardiol. 2001;37(5):1478-92.
22. Tearney GJ, Regar E, Akasaka T, et al. Consensus standards for acquisition, measurement, and reporting of intravascular optical coherence tomography studies: a report from the International Working Group for Intravascular Optical Coherence Tomography Standardization and Validation. J Am Coll Cardiol. 2012;59(12):1058-72.

23. Ni J, Bongers A, Chamoli U, Bucci J, Graham P, Li Y. In Vivo 3D MRI measurement of tumour volume in an orthotopic mouse model of prostate cancer. Cancer Control. 2019;26(1):1073274819846590.

24. Nakazawa G, Yazdani SK, Finn AV, Vorpahl M, Kolodgie FD, Virmani R. Pathological findings at bifurcation lesions: the impact of flow distribution on atherosclerosis and arterial healing after stent implantation. J Am Coll Cardiol. 2010;55(16):1679-87.

25. Burke AP, Kolodgie FD, Zieske A, Fowler DR, Weber DK, Varghese PJ, Farb A, Virmani R. Morphologic findings of coronary atherosclerotic plaques in diabetics: a postmortem study. Arterioscler Thromb Vasc Biol. 2004;24(7):1266-71.

26. Sano K, Kawasaki M, Okubo M, Yokoyama H, Ito Y, Murata I, Kawai T, Tsuchiya K, Nishigaki K, Takemura G, Minatoguchi S, Zhou X, Fujita H, Fujiwara $\mathrm{H}$. In vivo quantitative tissue characterization of angiographically normal coronary lesions and the relation with risk factors: a study using integrated backscatter intravascular ultrasound. Circ J. 2005;69(5):543-9.

27. Ledru F, Ducimetière P, Battaglia S, Courbon D, Beverelli F, Guize L, Guermonprez JL, Diébold B. New diagnostic criteria for diabetes and coronary artery disease: insights from an angiographic study. J Am Coll Cardiol. 2001;37(6):1543-50

28. Araki T, Nakamura M, Utsunomiya M, Sugi K. Visualization of coronary plaque in type 2 diabetes mellitus patients using a new $40 \mathrm{MHz}$ intravascular ultrasound imaging system. J Cardiol. 2012;59(1):42-9.

29. Nasu K, Tsuchikane E, Katoh O, Fujita H, Surmely J, Ehara M, Kinoshita Y, Tanaka N, Matsubara T, Asakura Y, Asakura K, Terashima M, Suzuki T. Plaque characterization by virtual histology intravascular ultrasound analysis in patients with type 2 diabetes. Heart. 2008;94(4):429-33.

30. Nicholls SJ, Tuzcu EM, Kalidindi S, Wolski K, Moon KW, Sipahi I, Schoenhagen P, Nissen SE. Effect of diabetes on progression of coronary atherosclerosis and arterial remodeling: a pooled analysis of 5 intravascular ultrasound trials. J Am Coll Cardiol. 2008;52(4):255-62.

31. Feng T, Yundai C, Lian C, Zhijun S, Changfu L, Jun G, Hongbin L. Assessment of coronary plaque characteristics by optical coherence tomography in patients with diabetes mellitus complicated with unstable angina pectoris. Atherosclerosis. 2010;213(2):482-5.

32. Kato K, Yonetsu T, Kim SJ, Xing L, Lee H, McNulty I, Yeh RW, Sakhuja R, Zhang S, Uemura S, Yu B, Mizuno K, Jang IK. Comparison of nonculprit coronary plaque characteristics between patients with and without diabetes: a 3-vessel optical coherence tomography study. JACC Cardiovasc Interv. 2012;5(11):1150-8.

33. Fracassi F, Crea F, Sugiyama T, Yamamoto E, Uemura S, Vergallo R, Porto I, Lee H, Fujimoto J, Fuster V, Jang IK. Healed Culprit Plaques in Patients With Acute Coronary Syndromes. J Am Coll Cardiol. 2019;73(18):2253-63.

34. Arora S, Ofstad AP, Ulimoen GR, Birkeland Kl, Endresen K, Gullestad L, Johansen OE. Asymptomatic coronary artery disease in a Norwegian cohort with type 2 diabetes: a prospective angiographic study with intravascular ultrasound evaluation. Cardiovasc Diabetol. 2019;18(1):26.

35. Du R, Zhang RY, Lu L, Shen Y, Pu LJ, Zhu ZB, Zhang Q, Hu J, Yang ZK, Ding FH, Zhang JS, Shen WF. Increased glycated albumin and decreased esRAGE levels in serum are related to negative coronary artery remodeling in patients with type 2 diabetes: an Intravascular ultrasound study. Cardiovasc Diabetol. 2018;17(1):149.

36. De Rosa R, Vasa-Nicotera M, Leistner DM, Reis SM, Thome CE, Boeckel JN, Fichtlscherer S, Zeiher AM. Coronary Atherosclerotic Plaque Characteristics and Cardiovascular Risk Factors - Insights From an Optical Coherence Tomography Study. Circ J. 2017;81(8):1165-73.

37. Sheng Z, Zhou P, Liu C, Li J, Chen R, Zhou J, Song L, Zhao H, Yan H. Relationships of coronary culprit-plaque characteristics with duration of diabetes mellitus in acute myocardial infarction: an intravascular optical coherence tomography study. Cardiovasc Diabetol. 2019;18(1):136.

38. Gupta S, Maratha A, Siednienko J, Natarajan A, Gajanayake T, Hoashi S, Miggin S. Analysis of inflammatory cytokine and TLR expression levels in Type 2 Diabetes with complications. Sci Rep. 2017;7(1):7633.

39. Gleißner CA, et al. The vulnerable vessel, Vascular disease in diabetes mellitus. Hamostaseologie. 2015;35(3):267-71. 
40. Reith S, Milzi A, Lemma ED, Dettori R, Burgmaier K, Marx N, Burgmaier M. Intrinsic calcification angle: a novel feature of the vulnerable coronary plaque in patients with type 2 diabetes: an optical coherence tomography study. Cardiovasc Diabetol. 2019;18(1):122.

41. Lee HM, Kim JJ, Kim HJ, Shong M, Ku BJ, Jo EK. Upregulated NLRP3 inflammasome activation inpatients with type 2 diabetes. Diabetes. 2013;62(1):194-204.

42. Helderman F, Segers D, de Crom R, Hierck BP, Poelmann RE, Evans PC, Krams R. Effect of shear stress on vascular inflammation and plaque development. Curr Opin Lipidol. 2007;18(5):527-33.

43. Koskinas KC, Chatzizisis YS, Baker AB, Edelman ER, Stone PH, Feldman CL. The role of low endothelial shear stress in the conversion of atherosclerotic lesions from stable to unstable plaque. Curr Opin Cardiol. 2009;24(6):580-90.

44. Chatzizisis YS, Coskun AU, Jonas M, Edelman ER, Feldman CL, Stone $\mathrm{PH}$. Role of endothelial shear stress in the natural history of coronary atherosclerosis and vascular remodeling: molecular, cellular, and vascular behavior. J Am Coll Cardiol. 2007:49(25):2379-93.

45. Stone PH, Saito S, Takahashi S, Makita Y, Nakamura S, Kawasaki T, Takahashi A, Katsuki T, Nakamura S, Namiki A, Hirohata A, Matsumura T, Yamazaki S, Yokoi H, Tanaka S, Otsuji S, Yoshimachi F, Honye J, Harwood D, Reitman M, Coskun AU, Papafaklis MI, Feldman CL. PREDICTION Investigators. Prediction of progression of coronary artery disease and clinical outcomes using vascular profiling of endothelial shear stress and arterial plaque characteristics: the PREDICTION study. Circulation. 2012;126(2):172-81.

46. Slager CJ, Wentzel JJ, Gijsen FJ, Thury A, van der Wal AC, Schaar JA, Serruys PW. The role of shear stress in the destabilization of vulnerable plaques and related therapeutic implications. Nat Clin Pract Cardiovasc Med. 2005;2(9):456-64.

47. Groen HC, Gijsen FJ, van der Lugt A, Ferguson MS, Hatsukami TS, van der Steen AF, Yuan C, Wentzel JJ. Plaque rupture in the carotid artery is localized at the high shear stress region: a case report. Stroke. 2007;38(8):2379-81

48. Fukumoto Y, Hiro T, Fujii T, Hashimoto G, Fujimura T, Yamada J, Okamura T, Matsuzaki M. Localized elevation of shear stress is related to coronary plaque rupture: a 3-dimensional intravascular ultrasound study with in vivo color mapping of shear stress distribution. J Am Coll Cardiol. 2008;51(6):645-50,

49. Gijsen FJ, Mastik F, Schaar JA, Schuurbiers JC, van der Giessen WJ, de Feyter PJ, Serruys PW, van der Steen AF, Wentzel JJ. High shear stress induces a strain increase in human coronary plaques over a 6-month period. Eurolntervention. 2011;7(1):121-7.

50. Gijsen FJ, Wentzel JJ, Thury A, Mastik F, Schaar JA, Schuurbiers JC, Slager CJ, van der Giessen WJ, de Feyter PJ, van der Steen AF, Serruys PW. Strain distribution over plaques in human coronary arteries relates to shear stress. Am J Physiol Heart Circ Physiol. 2008;295(4):H1608-14.

51. Chatzizisis YS, Baker AB, Sukhova GK, Koskinas KC, Papafaklis MI, Beigel R, Jonas M, Coskun AU, Stone BV, Maynard C, Shi GP, Libby P, Feldman CL, Edelman ER, Stone PH. Augmented expression and activity of extracellular matrix-degrading enzymes in regions of low endothelial shear stress colocalize with coronary atheromata with thin fibrous caps in pigs. Circulation. 2011;123(6):621-30.

52. Chatzizisis $\mathrm{YS}$, Coskun $\mathrm{AU}$, Jonas $\mathrm{M}$, Edelman $E R$, Stone $\mathrm{PH}$, Feldman $\mathrm{CL}$. Risk stratification of individual coronary lesions using local endothelial shear stress: a new paradigm for managing coronary artery disease. Curr Opin Cardiol. 2007;22(6):552-64.

53. Samady H, Eshtehardi P, McDaniel MC, Suo J, Dhawan SS, Maynard C, Timmins LH, Quyyumi AA, Giddens DP. Coronary artery wall shear stress is associated with progression and transformation of atherosclerotic plaque and arterial remodeling in patients with coronary artery disease. Circulation. 2011;124(7):779-88.

54. Moncada S, Palmer RM, Higgs EA. Nitric Oxide: physiology, pathophysiology, and pharmacology. Pharmacol Rev. 1991;43(2):109-42.

55. Mäkimattila S, Virkamäki A, Groop PH, Cockcroft J, Utriainen T, Fagerudd J, Yki-Järvinen H. Chronic hyperglycemia impairs endothelial function and insulin sensitivity via different mechanisms in insulin-dependent diabetes mellitus. Circulation. 1996;94(6):1276-82.

\section{Publisher's Note}

Springer Nature remains neutral with regard to jurisdictional claims in published maps and institutional affiliations.
Ready to submit your research? Choose BMC and benefit from:

- fast, convenient online submission

- thorough peer review by experienced researchers in your field

- rapid publication on acceptance

- support for research data, including large and complex data types

- gold Open Access which fosters wider collaboration and increased citations

- maximum visibility for your research: over $100 \mathrm{M}$ website views per year

At BMC, research is always in progress.

Learn more biomedcentral.com/submissions 